\title{
La Economía Social en tiempos de austeridad: el caso portugués
}

\author{
Fernando Ampudia de Haro \\ Professor Auxiliar de la Universidade Europeia-Laureate International Universities / \\ CIES-Instituto Universitário de Lisboa (Lisboa, Portugal) \\ fernando.ampudia@universidadeeuropeia.pt
}

DOI: $10.1387 /$ reves. 17646

Fecha de entrada: 30/04/2017

Fecha de aceptación: 04/06/2017

\begin{abstract}
Sumario: Introducción. 1. Economía Social, políticas públicas y políticas de austeridad: ¿qué relaciones? 1.1. El concepto de Economía Social. 1.2. Economía Social y políticas públicas. 1.3. La Economía Social en Portugal: una visión panorámica. 1.4. Las políticas de austeridad. 2. Apunte metodológico. 3. La visión de la Economía Social en tiempos de austeridad. 3.1. Ajuste y emergencia: el encuadramiento de la Economía Social en un contexto de austeridad. 3.2. El Programa de Emergencia Social y el nuevo paradigma de articulación con la Economía Social. 3.3. La ética social en la austeridad. 4. La Economía Social como paliativo. 5. Conclusión. 6. Referencias bibliográficas
\end{abstract}

\section{Resumen:}

Durante la aplicación del programa de ajuste económico-financiero, el XIX Gobierno Constitucional portugués (PSD/CDS, 2011-2015) reivindicó la Economía Social (ES) como medio principal para responder a la situación de crisis vivida por el país. El objetivo de este artículo es analizar la visión proyectada de la ES desde el poder político en lo que toca a sus funciones, su articulación con las políticas públicas y su justificación moral. De este modo, se identifica el papel atribuido a la ES en un contexto de crisis a la vez que se determina en qué medida es posible discursivamente compatibilizar las iniciativas propias de la ES y las denominadas políticas de austeridad.

Este trabajo toma como material empírico de referencia la producción documental del XIX Gobierno sobre la ES así como la comunicación pública de sus iniciativas en este terreno. Dicho material se analiza críticamente con el objeto de reconstruir la visión gubernamental de la ES como herramienta de combate al impacto social de la crisis. En un contexto de austeridad caracterizado por la desinversión en el sistema público de bienestar, el aumento del desempleo y el incremento de las formas de pobreza y exclusión social, dicha visión se asocia a la 
idea de paliativo frente a las insuficiencias de la acción estatal y las asimetrías del mercado.

\title{
Palabras clave:
}

Economía Social; Austeridad; Políticas Públicas; Portugal.

\begin{abstract}
:
The Social Economy (SE) was explicit and frequently invoked by the $19^{\text {th }}$ Constitutional Government of Portugal (PSD/CDS, 2011-2015) during the implementation of the Economic Adjustment Program commissioned by the International Monetary Fund, the European Commission and the European Central Bank. In this sense, SE was presented as one of the main means to face the difficulties associated to the social and economic crisis.

The aim of this paper is to analyse the view on SE which was transmitted by the $19^{\text {th }}$ Government in this period in order to know what the role attributed to SE in a context of social crisis is, what its function in terms of public policies is and what its ethical justification according to the political power is. Thus, this work examines how is constructed, in terms of political discourse, the compatibility between SE and austerity policies.

The empirical base of this article is constituted by official documents produced by the $19^{\text {th }}$ Government about SE as well as public communications on governmental initiatives related to SE as a response to social crisis. This documental set is analysed according to a critical approach in order to extract the scope, the mission and the range indorsed to SE by the political power. In a context dominated by austerity policies and characterized by a selective disinvestment in public welfare, rising unemployment and the increase of poverty and social exclusion, SE is seen by the governments as a palliative resource against the state limitations and the market asymmetries.
\end{abstract}

\section{Keywords:}

Social Economy; Austerity; Public Policies; Portugal.

\section{Claves Econlit:}

A130, I390, Z130.

\section{Introducción}

Entre Mayo de 2011 y Junio de 2014, Portugal vivió sujeto a las directrices del Programa de Asistencia Económica y Financiera (PAEF) acordado con la Comisión Europea (CE) y el Fondo Monetario Internacio- 
nal (FMI). A cambio de 78 mil millones de euros, el país se comprometía a aplicar un conjunto de medidas que perseguían, de acuerdo con fuentes oficiales, «(...) reestablecer la confianza de los mercados internacionales, (...) y promover la competitividad y el crecimiento económico sostenible» (Banco de Portugal, s.a.). El nuevo gobierno (XIX Gobierno Constitucional) surgido de las elecciones generales de Junio de 2011, una coalición formada por el Partido Socialdemócrata (PSD, centro-derecha liberal) y el Centro Democrático Social-Partido Popular (CDS-PP, derecha conservadora), declaraba sin ambages su compromiso con la ejecución del PAEF (Público, 2011). El programa de medidas del XIX Gobierno Constitucional también contenía una promesa que, por aquel entonces, pasaría desapercibida para la opinión pública: el ejecutivo liderado por Pedro Passos Coelho apelaba explícitamente a las organizaciones de Economía Social (ES) como medio de respuesta a los problemas generados o agravados por la crisis económico-financiera:

No dejaremos a nadie atrás. El valor inconmensurable de la dignidad humana nos obliga a preocuparnos por auxiliar a los más vulnerables y a un reparto justo de los costes y sacrificios asociados a la superación de la crisis y al propio proyecto de cambio que orienta las politicas del Gobierno. (Presidência do Conselho de Ministros, 2011: 85-86)

A primera vista, esta reivindicación de la ES puede parecer extraña en un gobierno decidido a aplicar un conjunto amplio de políticas de austeridad. Basadas en la devaluación interna como instrumento de competitividad, la retracción del Estado, la liberación de la energía emprendedora de la iniciativa privada y la dinamización de los mercados, estas políticas divergen de los proyectos de naturaleza socializante de la ES, de sus pretensiones de democracia organizativa y equidad distributiva así como de la defensa del principio de reciprocidad como principio de gobernación económica. Muy a pesar de esa extrañeza, para el XIX Gobierno Constitucional portugués, la convergencia entre aquellas políticas y la ES sí parecía posible. Es decir, la apuesta por la ES formó parte de las políticas públicas desarrolladas en tiempo de crisis y ajuste económico-financiero.

El objetivo de este trabajo es, precisamente, analizar críticamente esa convergencia. Si, como apuntaba anteriormente, la ejecución del PAEF fue prioritaria para el gobierno, la vindicación de la ES fue posible en la medida en la que algunos de sus postulados fueron adaptados a las exigencias de las políticas de austeridad. La cuestión que se plantea es saber cómo se construye discursivamente tal compatibilidad y qué papel le estuvo reservado a la ES en el ajuste económico y financiero portugués. Con este fin, 
se toma como material empírico de referencia un conjunto de documentos oficiales alusivos a la ES que tienen su origen en la esfera gubernamental $o$ en las iniciativas concertadas entre el XIX Gobierno y representantes específicos del sector de la ES. Mediante el análisis de ese material es posible identificar la visión que se proyecta de la ES desde el poder, esto es, cómo se encuadra en un contexto de austeridad, qué articulación se propone con las políticas públicas y qué tipo de valores justifican tal articulación. De este modo, nos situamos en un terreno en el que se cruzan tres áreas temáticas fundamentales: la Economía Social, las políticas públicas y el discurso político acerca de la crisis; tres cuestiones prioritarias en el debate intelectual, ideológico y normativo de los últimos tiempos.

De acuerdo con el objetivo establecido, el artículo se divide en cuatro partes. En la primera, se establece el marco teórico y conceptual que estructura el análisis. Ello supone abordar las relaciones existentes entre las tres áreas temáticas que vertebran la exposición, a saber, la Economía Social, las políticas públicas y las políticas de austeridad. Se efectúa además una breve caracterización del panorama pasado y presente de la ES en el país vecino. El discurso del XIX Gobierno es claro en ese sentido: las organizaciones de ES deben funcionar activamente como salvaguardia de la población más castigada por la crisis. De este modo, se da continuidad a un vínculo entre la providencia estatal y la ES que se articula históricamente de forma variable.

La segunda parte corresponde a la sección metodológica y en ella se presenta el material documental que se analiza justificando además su pertinencia. Asimismo, se explicita la estrategia de análisis y las dimensiones que son objeto de estudio. Globalmente, dicha estrategia parte de una aproximación crítica al discurso del XIX Gobierno en lo que toca a los valores, la visión y la misión atribuidos a la ES en un contexto de crisis.

En la tercera parte se analiza el discurso del XIX Gobierno con el propósito de reconstruir su visión sobre la ES. Esa visión incluye a) una caracterización general de la situación del país a partir de la cual se apela a la intervención de las organizaciones de la ES; b) iniciativas gubernamentales específicas como el Programa de Emergencia Social, articulado y ejecutado a través de tales organizaciones; c) una propuesta de articulación entre el Estado y el sector de la ES como medio de organizar y proporcionar servicios de protección social; y d) una justificación moral de ese llamamiento a la ES como racionalización normativa de las medidas gubernamentales de política pública.

En la cuarta y última parte se discuten los resultados del análisis destacando dos aspectos fundamentales. Primero, evaluando la posibilidad de que para el XIX Gobierno la ES fuese, fundamentalmente, una economía de tipo paliativo que corrige y compensa las ausencias del Estado y los fa- 
llos del mercado. Segundo, considerando los riesgos de instrumentalización de la ES al servicio de las denominadas políticas de austeridad.

\section{Economía Social, políticas públicas y políticas de austeridad: ¿qué relaciones?}

\subsection{El concepto de Economía Social}

La definición del concepto de Economía Social no es ajena al debate teórico. Con todo, no figura entre los objetivos de este artículo ilustrar ese debate (Chaves y Monzón, 2001). Por ese motivo, parto de una definición meramente operativa que permita abordar con garantías el caso portugués. De acuerdo con Defourny (2009) y Monzón y Chaves (2012), el espacio de la ES está integrado por organizaciones privadas que reúnen las siguientes características:

a) Tienen como finalidad ofrecer bienes y servicios a sus miembros o a la colectividad. Tales bienes y servicios también pueden ser vendidos en el mercado. Otra posibilidad es que sean encaminados a las economías domésticas que, actuando como consumidores, pueden pagar integral o parcialmente el precio de los mismos.

b) Poseen una gestión autónoma y desarrollan procesos de decisión democrática basados en la lógica «una persona, un voto».

c) Priorizan las personas y el trabajo frente a la distribución de rentas derivadas de la actividad. Por esa razón, es habitual que los excedentes se reinviertan para asegurar la viabilidad de la organización. Se asume, pues, que la noción de excedente se diferencia del concepto de lucro, entendido como remuneración del capital en función de la inversión realizada.

d) La adhesión a la organización es voluntaria.

e) La organización es independiente de cualquier tipo de tutela, lo que no excluye la posibilidad de obtener financiación y apoyo de organismos públicos o privados.

f) Las fórmulas organizativas típicas son las cooperativas, las asociaciones y las mutualidades.

A pesar de este intento por delimitar adecuadamente el concepto, lo cierto es que, por ejemplo, presenta concomitancias con la noción de Sector No Lucrativo u Organizaciones sin Ánimo de Lucro (Non Profit Organizations), otro de los conceptos más empleados a la hora de referir esta realidad. Empero, la exigencia a sus dirigentes de un principio de altruismo puro como principio de autodefinición identitaria o la no obligatoriedad 
de un sistema de gestión democrática alejan substancialmente dicha noción del concepto de Economía Social (Powell e Steinberg, 2006; Salamon e Auheier, 1999). Pese a todo, en este terreno será necesario convivir con ciertas ambigüedades e indefiniciones, producto de la dificultad intrínseca de cualquier concepto para captar satisfactoriamente la pluralidad de los fenómenos económicos (Chaves, 1997).

En clave institucional y en términos de reconocimiento legal, administrativo y académico, el concepto de Economía Social se encuentra plenamente establecido en Portugal. Basta, como muestra, constatar la denominación de la ley que encuadra este tipo de actividades (Lei de Bases da Economia Social), el proyecto de contabilidad nacional del valor económico de estas organizaciones (Conta Satélite da Economia Social) o la propia oferta formativa en este dominio (Máster en Economia Social e Solidária en el ISCTE-Instituto Universitário de Lisboa o en la Universidade do Minho, Máster en Gestão de Organizaçôes de Economia Social en la Universidade Católica do Porto o la Post-graduación en Economia Social de la Universidade de Coimbra). Estos ejemplos no implican que tal reconocimiento sea un criterio unívoco a la hora de distinguir entre organizaciones que forman o no parte de la ES. Son ilustrativos, si se quiere, de la aceptación social del término aunque no nos eximan de considerar principios normativos estructuradores como la solidaridad, la democracia, la autonomía y la voluntariedad. Con todo y aun tratándose de un concepto consolidado, veremos cómo el XIX Gobierno lo utiliza junto a otros que funcionan en su discurso como sinónimos, a saber, «tercer sector», «sector solidario» $\mathrm{O}$ «sector social».

\subsection{Economía Social y políticas públicas}

Las relaciones entre el Estado como promotor de políticas públicas y la ES son complejas y se hallan expuestas a diferentes tipos de equilibrio. En función de cómo se teorice esa articulación, tendremos una versión más o menos autónoma, dependiente o instrumental de la ES en el campo de las políticas públicas. De acuerdo con la más reciente aportación de Laville e Nyssens (2016), tal articulación puede ser de tres tipos: tutelada, acordada o competitiva.

Cuando la articulación es tutelada, el Estado fija unilateralmente los objetivos, los servicios, las normas y la modalidad de financiación de las políticas públicas. Establecido de este modo, cabrá a las organizaciones de ES la prestación de tales servicios siempre en posición subordinada en relación a la iniciativa estatal (Hespanha y Lucas dos Santos, 2016): ni la población potencialmente beneficiaria ni aquellas organizaciones intervienen 
en la determinación de prioridades. En este punto, la ES no encarna la autonomía de la sociedad civil y prescinde de su proyecto de democracia directa y deliberativa.

Desde una óptica competitiva, el Estado define el marco legal donde operan las organizaciones de ES. Estas, adoptando una lógica de competición, pugnan por la prestación de servicios. Se configura un casi-mercado de políticas públicas comúnmente relacionado con la desactivación del Estado de Bienestar y una visión del ciudadano como cliente-consumidor. Se reivindica instrumentalmente la ES para ocupar el espacio de un Estado que se retira como proveedor directo de protección social. Esta instrumentalización no tiene un origen exclusivamente estatal. También las empresas, mediante el modelo del Social Business, poden utilizar las organizaciones de ES como un medio para legitimar el sistema capitalista bajo el formato de filantropía eficiente gestionada con arreglo a principios «manageriales». Incluida en esta categoría encontramos las propuestas de la Tercera Vía, cuya formulación más conocida corresponde a Anthony Giddens (1998). En ella se defiende la posibilidad de un Estado de Inversión Social (Social Investment State) en el que la producción y distribución de servicios de bienestar y protección se efectúe a partir de combinaciones entre el Estado y las organizaciones de la ES, correspondiendo al primero la tarea de replicar el dinamismo del mercado en este campo y combatir la rigidez administrativa.

Un tipo de articulación acordada conlleva la construcción conjunta de políticas públicas entre el Estado y la ES definiendo criterios de intervención y utilidad. Aquí el Estado sí reconoce en las organizaciones de la ES la condición de interlocutores válidos y representantes de la sociedad civil. El desafío es lograr la compatibilidad de la solidaridad horizontal — basada en la reciprocidad y característica de la ES - con la solidaridad vertical - basada en la redistribución y característica del Estado- desestimando la solidaridad filantrópica de cariz asistencialista (Laville, 2016).

En cualquier caso, estas modalidades de articulación aparecen aquí expuestas como prototipos puros que nunca se concretan empíricamente de forma literal. Como sucede con el caso portugués, existen elementos que encajan en las tres modalidades sin que ello signifique que no pueda detectarse una tendencia general. Históricamente, tal articulación fue frecuentemente tutelada, adoptó una versión acordada con la caída de la dictadura y la implantación de la democracia e introdujo, desde los años 90, fórmulas competitivas. En este sentido, pueden distinguirse las siguientes fases:

—Estado Novo (1933-1974): Antes de 1933 ya existían diferentes manifestaciones de la ES (Quintáo, 2011). Es el caso de las cooperativas que se desarrollan con la emergencia de la cuestión social desde 
el siglo XIX, reconocidas jurídicamente en 1867 y que alcanzarían las 340 unidades en la década de 1920. También el de las mutualidades, que en 1931 contaban con 576 mil miembros en todo el país. Con la llegada de Oliveira Salazar al gobierno y la implantación del régimen dictatorial, el Estado adoptó una posición subsidiaria en la provisión de bienes y servicios de protección social a la población (Joaquim, 2015). Estatal y formalmente, se reconocía la importancia de las instituciones de solidaridad social mas concernía exclusivamente a ellas la producción y distribución de bienes y servicios a los más necesitados. De entre las organizaciones de ES, el régimen toleraba las mutualidades y las asociaciones con vocación asistencial y reprimía las cooperativas, sospechosas de subversión de los valores tradicionales dada la preferencia de la izquierda política por esta forma de organización del trabajo. En general, es un período de articulación tutelada en el que, según las directrices estatales, las organizaciones de ES desarrollan su actividad con arreglo a patrones asistencialistas, corporativistas y caritativos.

- Revolución de los Claveles (1974-1975): Se produce una alteración substancial con relación al paradigma anterior (Quintão, 2011). La intensa movilización de la sociedad civil y la influencia ejercida por los modelos de inspiración socialista condujeron a un crecimiento sin parangón de organizaciones de ES dirigidas a la satisfacción de necesidades básicas y a la corrección de los déficits que presentaba el país en los dominios de la salud, la vivienda, el empleo y la educación (Varela, 2014). Al tiempo, comienza a construirse un sistema de protección social universal que se materializará en la Constitución de 1976 (Rodrigues, 2010) y que incluye leyes en materias como el subsidio de desempleo, el derecho laboral, la protección contra la enfermedad o la invalidez, el salario mínimo, las pensiones o la financiación de la Seguridad Social. Las organizaciones de ES y el Estado adoptan un sistema de colaboración relativamente igualitario si bien, con frecuencia, el dinamismo de la ES sobrepasó a la acción estatal modelando políticas públicas que, a posteriori, serán legalmente reconocidas.

- Post-revolución e estabilización democrática (1976-década de los años 90). La institucionalización de la democracia liberal representativa está asociada a la edificación de un sistema de bienestar por iniciativa estatal (Joaquim, 2015). En este proceso, las organizaciones de ES son reconocidas como piezas esenciales en la producción y provisión de servicios y bienes de protección social. Esto motivará un fortalecimiento de la cooperación entre el Estado y dichas organizaciones, especialmente las Instituciones Particulares de Solida- 
ridad Social (IPSS), fundamentales, como veremos, en el discurso del XIX Gobierno. En 1979 se instituye el Estatuto de las IPSS y un año después se reglamenta el procedimiento de colaboración con el Estado mediante los llamados Protocolos de Colaboración. Estos protocolos se traducen en cobertura financiera estatal para que las IPSS ejecuten sus actividades de acción social, centradas en el apoyo a la infancia, familias necesitadas, tercera edad, minusvalía física y psíquica y medicina preventiva (Joaquim, 2015). En 1996 se establece el Pacto de Cooperación para la Solidaridad Nacional, mediante el cual la administración central, regional y local y las instituciones sociales se comprometían a crear una red a escala nacional para optimizar los recursos estatales, pero también los de las propias instituciones. En el año 2000, las Bases Generales del Sistema de Solidaridad y Seguridad Social refuerzan la tutela estatal con el poder de fiscalización e inspección sobre las IPSS. En síntesis, esta fase representa la persistencia de una lógica y de un discurso de articulación acordada entre el Estado y la ES que constituye la antesala para una posterior introducción de elementos competitivos.

—Estabilización y reforma del Sistema de Bienestar (2000-hasta hoy). Se edifica una relación de cooperación privilegiada entre el Estado y la ES en la vertiente de las IPSS y estrechamente asociada al campo de la acción social. Los componentes asistencialistas, en retroceso desde los años 80, no desaparecen y conviven simultáneamente con la versión socialdemócrata, que ambiciona un sistema universal de protección social y la versión neoliberal, que ve en esa protección un incentivo a la no participación en el mercado de trabajo (Ferreira, 2013). Las denominadas políticas de austeridad acentúan este último enfoque, enfatizando la necesidad de reducir el gasto público $y$, específicamente, el de tipo social para apostar por una dinamización competitiva de las organizaciones de ES.

Como puede constatarse, la relación entre la ES y las políticas públicas es constante, especialmente en lo que toca a la edificación de un sistema de bienestar y protección social. En Portugal se detectan tendencias híbridas en las que se alternan modalidades de articulación, circunstancia que no es necesariamente igual a la de otros países europeos (Ferreira, 2013). En el espacio anglosajón, las organizaciones de ES desarrollan su actividad orientadas preferentemente al mercado mientras que los modelos corporativistas -Francia, Alemania, Austria- exhiben una tendencia más estatista, asumiendo el propio Estado la misión de proveer, fiscalizar y financiar. Una tercera posibilidad es la que ofrecen los países nórdicos, en los que la fortaleza del sistema estatal de protección y bienestar determina un menor de- 
sarrollo de las organizaciones de ES, más concebidas como canales de presión y reivindicación frente a los poderes públicos.

\subsection{La Economia Social en Portugal: una visión panorámica}

De acuerdo con la Ley de Bases de la Economía Social (Lei n. ${ }^{\circ}$ 30/2013, de 8 de mayo), las organizaciones que componen el sector de la ES son las cooperativas, las mutualidades, las asociaciones, las fundaciones, las IPSS y las misericordias. Así como las cuatro primeras resultan familiares para el lector especializado y por ello no será necesaria una explicación generalista, las dos últimas sí merecen una caracterización adicional dada su particularidad.

Las misericordias son organizaciones específicamente portuguesas cuyo origen data del siglo XviII. Se dedican prioritariamente a la satisfacción de carencias sociales - salud, residencias de ancianos y centros de día/noche, centros de acogida - y se hallan estrechamente vinculadas a la Iglesia católica.

Por su parte, las IPSS no son estrictamente una forma organizativa y sí un estatuto jurídico concedido a entidades que son la expresión organizativa de la solidaridad nacida de la sociedad civil. Según la Cuenta Satélite de la Economía Social (CASES, 2013), de entre las 55 mil organizaciones de la ES contabilizada en Portugal, 5000 poseen este estatuto. De ellas, la mayoría son asociaciones $(84,3 \%)$, seguidas de Misericordias (6,8\%), Fundaciones $(4,2 \%)$, Mutualidades $(2,4 \%)$ y Cooperativas $(2,3 \%)$. Las Instituciones Particulares de Solidaridad Social prestan servicios de apoyo, sobre todo, a deficientes psíquicos y físicos, ancianos y familias en áreas relacionadas con la salud, la educación, la vivienda y la integración social. Están parcialmente financiadas por la Seguridad Social mediante protocolos bianuales de cooperación y muchas tienen capacidad para generar ingresos propios gracias a la venta total o parcial en el mercado de sus productos y servicios.

En lo que se refiere al significado macroeconómico de la ES en Portugal, la Cuenta Satélite de la Economía Social (CASES, 2013) proporciona la información más completa de la que disponemos hasta la fecha, pese a que sus datos originales se remonten al año 2010:

—Existen 2.260 cooperativas, 119 mutualidades, 381 misericordias y 52.086 asociaciones.

- El Valor Añadido Bruto (VAB) de la ES equivale al 2,8 del VAB portugués. El sector concentra 5,5\% del empleo remunerado. La remuneración media corresponde al $83 \%$ de la remuneración media nacional. 
- Del total de las organizaciones de la ES, 94\% son asociaciones, que representan el 54\% del VAB de la ES y el 65\% del empleo en el sector.

- El $64,4 \%$ de las organizaciones desarrolla su actividad encuadrada en la categoría de 'acción social' (incluye servicios de carácter humanitario y ayuda a individuos con minusvalías, ancianos y jubilados, familias, público infantil-juvenil; entidades de emergencias y rescate como los retenes voluntarios de bomberos y bancos de alimentos). Esta categoría genera el $41,3 \%$ del VAB de la ES y representa el $48 \%$ del empleo remunerado.

- Hay 5022 IPSS, que generan el 50\% del VAB de la ES y el $42,6 \%$ de las remuneraciones. En ellas se concentra el 38,2\% de las necesidades netas de financiación de la ES. Su actividad fundamental también se integra en la categoría de «acción social» —el 64\% responde a esa característica - y el $62 \%$ de su financiación responde a la venta y producción de bienes y servicios. De acuerdo con Almeida (2011), el 70\% de los servicios en el campo de la acción social - jardín de infancia, guarderías, centros de día y de noche, residencias para la tercera edad o apoyo en domicilio - lo asumen las IPSS a nivel local, circunstancia que explica por qué, en términos de gastos e ingresos, muchas poseen un volumen superior a la media de las empresas de las zonas donde se localizan.

- El 63\% de los recursos de las organizaciones de la ES se genera mediante la venta de bienes y servicios mientras que un $24 \%$ procede de transferencias estatales y de subsidios a la producción.

\subsection{Las politicas de austeridad}

Entre 2011 y 2015, las políticas de austeridad configuran el contexto general en el que se desarrolla la articulación que el XIX Gobierno propone entre la ES y las políticas públicas. Oficialmente, en este período, Portugal vive con arreglo a los requisitos del PAEF y sus exigencias en clave de consolidación presupuestaria y estabilización de las cuentas públicas. Lo cierto es que tales políticas no comienzan estrictamente en 2011: existen precedentes significativos en la segunda legislatura del XVIII Gobierno Constitucional - del Partido Socialista, con José Sócrates como Primer Ministro- dentro de los llamados Planes de Estabilidad y Crecimiento I, II y IV presentados entre 2010 y 2011. Con todo, será durante el XIX Gobierno cuando adquieran un peso dominante en la organización y marcha del país.

Según Blyth (2013), las políticas de austeridad son a) políticas que promueven intencionalmente procesos de deflación mediante los cuales, b) la 
economía sufre un proceso de ajuste gracias a la reducción de los salarios, los precios y el gasto público, c) con el propósito de restablecer la competitividad de la economía, d) la cual, en virtud de la disminución del déficit, la deuda y la despensa pública, e) provoca un aumento de la confianza de los inversores, pues la contención impide que el Estado absorba todas las posibilidades de financiación, f) y, por extensión, una expansión de la actividad económica. En definitiva, estamos ante políticas que pretenden provocar un efecto expansionista en la actividad económica mediante una contracción sostenida de sus componentes. Dichas políticas poseen legitimación científico-académica (Alesina e Ardagna, 1998) y cuentan con destacados apoyos en organismos internacionales como el Fondo Monetario Internacional, el Banco Mundial, la Unión Europea o el Banco Central Europeo. Se presentan como un conjunto de resoluciones técnicas investidas de objetividad que proporcionan una solución a los problemas económicos: su pedigrí científico las torna unívocas e indiscutibles (Fourcade, Ollion y Algan, 2015; Colander, 2005). El consenso sobre las mismas es amplio en sectores políticos, financieros y mediáticos con capacidad de acción e influencia, lo que explica que se hayan presentado como políticas aptas para resolver la crisis iniciada en Estado Unidos en 2008 como crisis de las hipotecas subprime transmutada desde 2010 en crisis europea de las deudas soberanas. Con todo, no dejan de ser precisamente eso, una apuesta política por una línea específica de acción económica en un contexto también específico que se juzga favorable a su aplicación (Freire, 2013; Mamede, 2015). Como demuestra Freire (2013:87), la crisis constituye una «ventana de oportunidad» para ejecutar políticas de esta naturaleza, teóricamente impopulares dada su preferencia por la desvalorización salarial o el aumento de la presión fiscal sobre las clases medias y bajas, pero menos expuestas a la resistencia de la ciudadanía cuando se asocian a una coyuntura de emergencia.

Las políticas de austeridad no son sólo medidas económicas. Parte substancial de las mismas es el discurso que legitima su pertinencia, estructurado a partir de tres ideas centrales:

a) Es una práctica habitual del Estado la aplicación de políticas derrochadoras que van más allá de sus posibilidades materiales comprometiendo el presente y el futuro del país (Sequeiros, 2013).

b) La población ha vivido durante los últimos años por encima de su capacidad económica a partir, fundamentalmente, del crédito (Santos, 2013).

c) El gasto público es, generalmente, ineficaz e ineficiente y se asocia al desperdicio de recursos (Caldas, 2013).

Entrando en el terreno de las políticas concretas, estas son una contrapartida al préstamo de 78 mil millones de euros, aportados en sus dos 
terceras partes por la UE y correspondiendo el tercio restante al FMI. Las principales medidas aplicadas fueron (Moury e Freire, 2015):

a) Reducción del déficit público, que debía pasar del 5,9\% del PIB en 2011 al 3\% en 2013. Con ese propósito, serían reducidos los gastos operacionales de la administración, aplicados cortes en los salarios de los funcionarios públicos, paralizadas las nuevas contrataciones, incentivadas las jubilaciones anticipadas y ejecutados despidos en el aparato estatal. De igual modo, se redujo el subsidio de desempleo en montante y duración, las pensiones y se congelaban un conjunto amplio de prestaciones sociales. Por último, aumentaban los impuestos directos (IRPF e Impuesto de Sociedades) y los indirectos (IVA) así como las tasas de copago por los servicios sanitarios.

b) Corrección de los desequilibrios de un sector financiero extremadamente endeudado. Para este fin se reservaron 12 mil millones de euros.

c) Dinamización de la actividad económica. Se pretendía un aumento de la flexibilidad del mercado de trabajo y de la competitividad empresarial reduciendo las indemnizaciones por despido o cancelación de contrato, aumentando las horas de trabajo o aligerando los requisitos para despedir a trabajadores. Otro punto de interés era la abertura a la competencia de sectores protegidos —agua, telecomunicaciones, transportes, energía, servicios postales - mediante la privatización de empresas públicas o la venta de la participación del Estado en su capital.

\section{Apunte metodológico}

El objetivo de este artículo es analizar la visión de la ES proyectada por el XIX Gobierno Constitucional portugués. Por esa razón, se asume como objeto de estudio el discurso gubernamental oficial a través del cual se concreta esa visión, reconstruida a partir de material documental relevante.

El discurso gubernamental sitúa en un primer plano de la esfera pública diversos conceptos, explicaciones y justificaciones en pro de un modelo de ES que considera legítimo y que, simultáneamente, es legitimado por tener su origen y soporte en el gobierno (Hespanha, 2007). Así pues, la producción discursiva del poder gubernamental combina una intencionalidad descriptiva con otra de carácter prescriptivo; combinación clásica siempre que se aborda la relación entre política, ideología y discurso (Van Dijk, 2005a). Según la perspectiva de la homología, el discurso coincide con la práctica y, por ese motivo, expresa fidedignamente las intenciones de quien 
lo produce. Según la perspectiva de la ideología, el discurso justifica los motivos de la práctica sin identificar los intereses que la sustentan, lo que permitiría que siendo de interés particular, pueda ser presentada como una iniciativa de interés general (Van Dijk, 2005b). Es cierto que ambas perspectivas resultan útiles para entender fenómenos de esta naturaleza, si bien resultan insuficientes si se pretende abordar posiciones híbridas como la que nos ocupa. El discurso gubernamental no determina unilateral y unívocamente una visión cerrada de la ES por dos razones. Primera, porque el significado de la ES también lo discuten los actores que integran el propio sector. Y segunda, porque el campo de la ES es heterogéneo, lo que permite identificar organizaciones y plataformas de organizaciones más próximas o alejadas de la visión proyectada por el poder político. Esto es, existe una negociación sobre el sentido de la ES en tiempos de austeridad si bien esta no forma parte del cometido de este trabajo. Con todo, es siempre importante señalar este aspecto para no incurrir en el reduccionismo de la unilateralidad que convierte el poder gubernamental en el único agente capaz de imponer significados acerca de la ES.

La reconstrucción del discurso gubernamental sobre la ES distingue tres dimensiones principales:

a) La caracterización del contexto socioeconómico en el que deben operar las organizaciones de la ES, del que deriva la justificación del papel y funciones que se le atribuyen.

b) El modelo pretendido de articulación entre el Estado, las políticas públicas y la ES.

c) Los valores que sostienen las reivindicación de la ES como respuesta a los desafíos que plantea el contexto socioeconómico.

La reconstrucción del discurso gubernamental se realiza a partir del siguiente material documental, agrupado en tres bloques:

a) El primer bloque lo integra la documentación específica producida por el XIX Gobierno acerca de la ES.

- Programa de Emergencia Social (PES) (MSSS, 2011). Documento privilegiado para estudiar el enfoque gubernamental, contiene una relación de medidas para enfrentar la crisis cuya ejecución correspondería a las organizaciones de ES además de los principios que rigen la colaboración entre estas y el Estado.

- Presentación pública del Programa de Emergencia Social (Soares, 2011). Tuvo lugar el 8 de mayo de 2011, cabiendo ese cometido al Ministro de Solidaridad y Seguridad Social, Pedro Mota Soares. Esta presentación permite conocer de primera mano la justificación y razones del propio programa en función de la na- 
turaleza de los problemas sociales que enfrenta el país así como constatar el llamamiento abierto y claro que efectúa el gobierno a la ES.

- Discurso de clausura del Primer Ministro en el I Congreso Internacional de la Economía Social. El 29 de junio de 2013, Pedro Passos Coelho (2013) se dirige a los asistentes a este evento estructurando su intervención en torno a la idea de la ES como medio principal de contrariar las consecuencias sociales de la crisis.

- Programa del XIX Gobierno Constitucional. Presentado y aprobado en la Asamblea de la República entre el 30 de junio y el 1 de julio de 2011. La preocupación por armonizar las medidas propias con las derivadas del Memorando de Entendimiento con el FMI y la CE es evidente a lo largo del documento, así como las referencias expresas a la Economía Social en el apartado de Seguridad Social y Solidaridad.

b) El segundo bloque de documentos recoge iniciativas conjuntas entre el Estado y representantes institucionales de la ES.

- Carta Común de Balance y Compromiso (CPSS, 2013). Suscrita por el Estado y una parte significativa de los representantes institucionales de la ES. Permite observar cómo la visión gubernamental de la ES también se construye en interacción con algunos de sus actores.

- Carta de Cascais para la Economía Social (CNES, 2013). Suscrita el 28 de Junio de 2013, anticipa el discurso que seis días más tarde profirió el Primer Ministro, Pedro Passos Coelho, en el cierre del I Congreso Internacional de la Economía Social.

- Discurso del Padre Lino Maia (Maia, 2011), Presidente de la Confederación Nacional de Instituciones de Solidaridad (CNIS), en las Jornadas Parlamentarias del CDS-PP (6 de septiembre de 2011). Inicialmente, esta intervención parece no encajar exactamente en este segundo bloque documental. Sin embargo, constituye un punto de encuentro, no directamente situado en la órbita estatal, entre un representante de la ES y un partido político que forma parte del XIX Gobierno Constitucional. El propio Lino Maia reconoce la participación del CNIS en la elaboración del Programa de Emergencia Social y su apoyo al mismo:

No coincidiendo exactamente con la propuesta de la CNIS, el PES es un programa que también tiene su marca, puesto que la CNIS y yo mismo colaboramos en él, leal y eficazmente, desde su concepción hasta su presentación 
pública. También estaremos con él a conciencia para una aplicación segura y eficaz. (Maia, 2011:1)

Este tipo de discurso permite observar el grado de sintonía entre las políticas de austeridad, las soluciones al impacto social de la crisis y el nivel de aceptación de las mismas entre sectores específicos de la ES.

c) El tercer bloque tiene un carácter exclusivamente auxiliar. Su cometido es apoyar o ilustrar aspectos específicos de los dos primeros bloques mediante noticias y declaraciones en los medios de comunicación sobre las iniciativas gubernamentales en materia de ES.

\section{La visión de la Economía Social en tiempos de austeridad}

\subsection{Ajuste y emergencia: el encuadramiento de la Economia Social en un contexto de austeridad}

Cualquier abordaje a la visión del XIX Gobierno portugués sobre la ES debe partir de un dato básico: la prioridad de la acción gubernativa es la ejecución del PAEF. Este es el punto de arranque que, inequívocamente, el gobierno adopta:

Se hace obligado el regreso, tan rápido como sea posible, a una trayectoria sostenible de las cuentas públicas que siente las bases de una economía próspera y creadora de empleo a medio plazo. Esto es, rigor y firmeza en las finanzas públicas para el crecimiento económico, la promoción del trabajo, la competitividad empresarial y la inclusión social. (Presidência do Consejo de Ministros, 2011:8)

El programa exige tiempo para alcanzar los resultados previstos y la aplicación conlleva una serie de costes que derivan de su inevitabilidad:

La pobreza se extiende. Aparecen nuevas formas alimentadas por el desempleo y el endeudamiento de las familias. En la coyuntura actual resulta impensable optar por caminos que disminuyan aún más los niveles de protección social de los más desfavorecidos o que impliquen un esfuerzo financiero adicional que el pais no puede soportar. (Presidência do Conselho de Ministros, 2011: 86)

De acuerdo con el gobierno, "Portugal pasa por una crisis gravísima que nos sitúa, como comunidad, en una de las encrucijadas más determinantes de nuestra historia reciente» (Presidência do Conselho de Ministros, 
2011: 11). En otras palabras, «(...) una situación de excepción» (Presidência do Conselho de Ministros, 2011: 11) que se manifiesta en todos los ámbitos, si bien con más énfasis en lo social y financiero. Las limitaciones de la acción gubernamental vienen dadas por los compromisos externos asumidos por el país. Cumplirlos resulta esencial para la recuperación:

En los próximos años, el ajuste de la economía portuguesa tendrá una exigencia sin precedentes históricos recientes. La corrección de los desequilibrios financieros externos e internos es la prioridad del Gobierno. El objetivo primordial es el regreso del pais a la financiación en condiciones normales de mercado. (Presidência do Conselho de Ministros, 2011: 21)

La coyuntura de excepcionalidad tiene una de sus manifestaciones más obvias en el área social. El Programa del XIX Gobierno Constitucional afirma explícitamente que Portugal vive una crisis social, lo que requiere acentuar el esfuerzo para atender «(...) a los más ancianos, a los que perdieron su puesto de trabajo, a los más necesitados, a los niños con dificultades, a los emigrantes y a las personas con deficiencias" (Presidência do Conselho de Ministros, 2011: 85). Para ese esfuerzo el gobierno es claro en sus intenciones: "Vamos a hacerlo con las instituciones de la Economía Social» (Presidência do Conselho de Ministros, 2011: 86).

\subsection{El Programa de Emergencia Social y el nuevo paradigma de articulación con la Economía Social}

El Programa de Emergencia Social (PES) estaba formado por un conjunto de medidas de combate a la crisis en el que se encuadran como ejecutantes las organizaciones de la ES. En este sentido, el PES no es estricta ni integralmente un programa de ES aunque cuenta con las organizaciones del sector como agentes de respuesta. Las características del programa, con especial atención a las dimensiones en las que la ES más se destaca, son las siguientes:

- En el terreno de la familia, el principal problema es el desempleo y sus consecuencias. Aquí, las organizaciones de la ES actúan como identificadoras de necesidades o directamente como entidades que ofrecen ocupación o empleo dada su proximidad a la población. Se proyecta la creación de programas de trabajo cívico y solidario para parados de larga duración y portadores de deficiencias o la apertura de líneas de crédito para constituir empresas sociales. No obstante, la medida más destacada es el Programa de Emergencia Alimenticia, 
que incluye a las organizaciones de ES en la ampliación de la red de comedores sociales con la misión de ofrecer comidas gratuitas a la población con menos recursos. La previsión era llegar a los 900 comedores con una partida de 50 millones de euros.

- En el terreno de la vejez, las instituciones de la ES son convocadas, de nuevo, en virtud de su proximidad a la población y, por lo tanto, de su conocimiento inmediato de la realidad. Contando con ellas, se proyecta la ampliación de la red de apoyo en domicilio, del sistema de tele-asistencia y de los centros de día y de noche.

- En el terreno de las minusvalías, se pretende un crecimiento de la empleabilidad de las personas así como la eliminación de barreras físicas y la mejora de la accesibilidad. También se incluye una iniciativa destinada al descanso de personas con dependientes (ancianos, enfermos) a su cargo.

- En el terreno del voluntariado se proyecta un plan nacional de sensibilización, un nuevo régimen jurídico y la creación de un complemento al título de enseñanza secundaria donde se registren las actividades de índole cívica.

- En el terreno de las instituciones sociales las iniciativas son variadas y por su interés para este artículo merecen una exposición más detallada:

- El 50\% del IVA asociado a obras e inversiones se devuelve a las instituciones.

- La vertiente de la acción social aumenta un 16\% (254 millones de euros) en relación a 2010. Los recursos totales disponibles en esta categoría son de 1846 millones de euros.

- El montante de los protocolos de cooperación con las IPSS aumenta un $1,3 \%$. La cantidad total inscrita en los Presupuestos Generales del Estado de 2012 es de 1200 millones de euros.

- El Estado salda su deuda de 5,7 millones de euros con las instituciones sociales.

- Se aumenta el número de plazas en guarderías y residencias de la tercera edad modificando la legislación.

- Se destinan 5 millones de euros a cursos de formación para directivos de instituciones con el cometido de mejorar su capacidad de gestión e innovación.

- Apertura de concursos públicos para transferir infraestructuras estatales a las IPSS. Especificamente, 40 de estas infraestruturas con, aproximadamente, 1200 personas.

Gran parte del discurso gubernamental sobre la ES tiene como eje el PES, tanto en la materialización de las medidas articuladas con las insti- 
tuciones, como en la capacidad que posee este documento para traducir la visión del XIX Gobierno. En este último nivel, resulta especialmente relevante la presentación pública del PES por Pedro Mora Sores, Ministro de Solidaridad y Seguridad Social. Junto a la explicación de cada una de las medidas, expone los principios que articularán el nuevo paradigma de respuesta social. La reivindicación de la ES se integra en ese paradigma: «(...) tenemos la humildad de pedir ayuda a las instituciones que en permanencia garantizan las respuestas sociales: las IPSS, las Misericordias y las $\mathrm{Mu}-$ tualidades», organizaciones que representan «(...) la línea de frente de la respuesta social que el país tiene» (Soares, 2011).

El nuevo paradigma parte de un diagnóstico sobre el sistema de protección y bienestar sociales que se basa en los siguientes puntos:

- El Estado desperdicia recursos mediante inversiones poco eficaces o ineficientes. Por esta razón, se hace necesario un sistema que racionalice las iniciativas estatales. Como afirma Pedro Mota Soares (2011), «(...) en algunos casos invertiremos más, en otros invertiremos mejor. También es posible, a partir de los montantes ya fijados, no gastar más, pero sí gastar mejor».

- El Estado alimenta una cultura de la dependencia que erosiona, elimina o no favorece la iniciativa personal. Esa cultura, encarnada prototípicamente por la figura del subsidio, promueve la inacción y el agotamiento injustificado de los recursos públicos. De nuevo, Pedro Mota Soares (2011) formaliza este argumento: «La sociedad portuguesa, que es humanista y generosa, quiere respuestas efectivas para los más pobres y por encima de cualquier consideración, quiere garantizar a todos una oportunidad basada en el valor del trabajo y no desea que el dinero de sus impuestos sea permeable al fraude y al abuso".

- El Estado, en virtud de su estructura y funcionamiento, impone rigideces administrativas que impiden u obstaculizan el desarrollo de respuestas sociales por parte de los agentes y las instituciones especializadas. La insistencia en la desburocratización se encuentra asociada a una hipotética liberación de energías de la ES. Una vez más, Mota Soares (2011) sintetiza esta idea con sus palabras:

Simplificando, desburocratizando, facilitando la vida a quien responde, a quien está en el terreno, a quien ayuda, aumentaremos la sostenibilidad de estas instituciones. $Y$ al hacerlo, fortalecemos el tercer sector, el sector social, dando condiciones para que, como ya ocurre, estimule la economía local, cree empleo y dinamice el interior donde muchas veces es de los pocos agentes económicos que existen. 
El propio Primer Ministro, Pedro Passos Coelho (2013), refuerza esta caracterización del Estado y de sus mecanismos de protección y bienestar, los cuales «(....) terminan por ser distantes, impersonales y burocráticos», en su discurso de clausura del I Congreso Internacional de la Economía Social.

- El Estado es poco riguroso y exigente consigo mismo en lo tocante a los servicios que presta y a su seguimiento y fiscalización. Como señala Pedro Mota Soares (2011), «(...) un Estado que tiene una perspectiva diferente y menos exigente para los servicios que presta directamente no es un Estado equitativo ni justo».

- El Estado, debido a esa falta de auto-exigencia, presenta un importante déficit en clave de voluntad y capacidad de gestión. Por este motivo, según Mota Soares (2011), es conveniente que los servicios de protección social no dependan del designio estatal: «En los Estados socialmente avanzados, la confianza en el Estado, en las IPSS certificadas y creíbles, es elevada, existiendo distinciones claras entre el prestador, el financiador y el regulador. El Estado no tiene vocación para dirigir».

En suma, según el discurso gubernamental, en este nuevo paradigma de respuesta social a la crisis, el Estado debe ser reformulado dadas sus limitaciones. Esa reformulación está relacionada con el papel atribuido a la ES como pieza esencial de aquel nuevo paradigma. De acuerdo con el Ministro de Solidaridad y Seguridad Social, este se estructura a partir de la noción de acuerdo público-social (parceria público-social), esto es, un régimen de colaboración entre la ES — con especial atención a las IPSS - y el Estado. Literalmente, Pedro Mota Soares lo explica del siguiente modo:

Es importante que el Estado sepa construir con las instituciones un nuevo paradigma de respuesta social. Algo que vaya más allá del tradicional wellfair (sic) public system, algo que outros já chamam um wellfair (sic) partnership system. (Agência Lusa, 2012)

De este modo, se pretende la conjunción del principio de subsidiariedad y el principio de colaboración. El primero pretende que las decisiones se tomen en el nivel más próximo al ciudadano. El segundo remite a los acuerdos establecidos entre los agentes que prestan servicios sociales. El PES sería representativo de tal conjunción: "Es un programa que no significa más Estado; significa, eso sí, más IPSS e mejor política social» (Soares, 2011). Este tipo de acuerdo público-social consiste en una transferencia financiera y de equipos o infraestructuras desde el sector público al sector de la ES, que actúa como prestador de servicios mientras el Estado asume la 
función de fiscalizador. He aquí el modelo que justifica la no creación de nuevas instituciones y sí la racionalización y maximización de las ya existentes: «No vamos a gastar en burocracia, vamos a invertir en las personas. No vamos a crear nuevas estructuras, vamos a rentabilizar las que tenemos» (Soares, 2011). Por su parte, el Primer Ministro, Pedro Passos Coelho, ve en esto una oportunidad para situar a la ES en el primer plano del combate a los efectos sociales de la crisis:

Si es verdad que el ajuste no nos ofrece el margen de maniobra que deseariamos para lidiar con estos problemas, no es menos cierto que este es el momento para situar a la Economía Social como un pilar del crecimiento económico y social de nuestro país. (Coelho, 2013)

\subsection{La ética social en la austeridad}

El nuevo paradigma viene acompañado de un discurso que legitima su validez. Conlleva diferentes consideraciones acerca de la protección debida a los sectores más frágiles de la población y la compatibilidad de esa protección con las exigencias del programa de ajuste económico-financiero. Se habla, pues, de ética social en la austeridad, un concepto que el Ministro de Solidaridad y Seguridad Social defendía en la I Convención Anual de la Plataforma Europea contra la Pobreza y la Exclusión Social (Agência Lusa, 2011a).

El concepto alude a la defensa de los más necesitados en un contexto de crisis y políticas de austeridad. De este modo, tales políticas aparecen asociadas a la preocupación por las consecuencias sociales que de ellas derivan. Pedro Passos Coelho refuerza esta idea en el I Congreso Internacional de la Economía Social: "Queremos una sociedad que no deje a nadie atrás. Esa es la divisa de una sociedad decente y moderna» (Coelho, 2013). Desde el poder gubernamental, es la definición más precisa con la que contamos. No existe una explicación más amplia y en todas las intervenciones de los responsables políticos, el concepto se menciona exclusivamente de manera genérica y sin un desarrollo extenso. Así lo hace Pedro Mota Soares cuando habla sobre la actualización de las pensiones mínimas, de las rurales y de las de invalidez (Jornal i, 2011), de los comedores sociales (Jornal de Notícias, 2012) o de las tarifas especiales de luz y gas:

En un momento en el que se le pide a los portugueses un conjunto de sacrificios adicionales para las personas más vulnerables y para las familias con menos recursos económicos, queremos que exista una ética social en la austeridad. Esto implica ofrecer un descuento social en consumos importantes como el de energía. (TSF, 2011) 
El gobierno no produce una explicación satisfactoria del concepto $y$, por ese motivo, es necesario salir de su esfera de acción directa para observar su zona de influencia, donde plataformas de ES adoptan el papel de interlocutor asumiendo la pertinencia de tal concepto. En este caso, no podemos hablar, stricto sensu, del discurso gubernamental, pero sí de un tipo de discurso afín y próximo que aborda con más precisión y detalle el componente moral de las políticas de austeridad.

Así sucede con el Presidente de la Confederación Nacional de las Instituciones de Solidaridad (CNIS), Lino Maia. Dos meses antes de las elecciones generales de 2015, la CNIS enviaba un documento, «Propuesta para un Programa Político de Gobierno», a todos los partidos que presentaban candidaturas. Al hilo de esta iniciativa, Pedro Passos Coelho solicitaba la colaboración de la CNIS en la elaboración del PES; solicitud que fue satisfecha. Así pues, el presidente de la CNIS constituye una voz autorizada para ilustrar el concepto de ética social en la austeridad. La intervención de Lino Maia en las Jornadas Parlamentarias del CDS-PP es especialmente apropiada en ese sentido.

En su exposición, define el PES como un instrumento al que subyace una «terapia de la realidad»: debe enfrentarse a las difíciles condiciones generadas por la crisis y el ajuste económico-financiero. Simultáneamente, la austeridad posee una función reparadora: «La austeridad es terapéutica porque ayuda a ver que el camino no será jamás un camino «folclórico»: el camino es el de que, cada uno, cuanto y cuando le sea posible, viva con el sudor de su rostro" (Maia, 2011). Esa función reparadora también se manifiesta en la cultura de dependencia alimentada por el Estado, a su vez relacionada con la concesión de favores que desincentivan la autonomía ciudadana: «(...) a costa del Estado Social se ha optado excesivamente por una continuada distribución de beneficios que muchas veces fomenta el hábito y la dependencia porque sus programas están exentos de una temporalidad que promueva la autonomía» (Maia, 2011).

El PES emerge como respuesta en este escenario dominado por la austeridad y la crisis. Sin embargo, el Presidente de la CNIS rechaza la acusación de ser éste un programa asistencialista o, mejor dicho, reformula el contenido de esa crítica. En una coyuntura de grandes dificultades es necesario «(...) que todo sea hecho por todos y que todo se use para asistir en la disminución del sufrimiento de aquellos que se consumen en la angustia de los tiempos presentes» (Maia, 2011). A partir de este instante, la conceptualización del PES y por extensión de la ES, entra en el dominio semántico del alivio: «El PES es un valioso instrumento para atenuar el sufrimiento. También para contrariar algún aumento de la pobreza y de sus manifestaciones» (Maia, 2011). Las respuestas a ese sufrimiento, relacionado con las dificultades generadas por la crisis, no es de cariz político: re- 
quiere un esfuerzo de índole moral que comienza en el individuo y que, por agregación, produce efectos virtuosos para toda la sociedad. Esta posición resulta claramente perceptible en la reflexión de Lino Maia sobre el rumbo, «liberalizador» o «socializador», que debe tomar el país:

Ciertamente, [Portugal no tiene] un rumbo ético en el que todos se impliquen en busca de lo bello, del bien y de lo bueno, que sólo lo serán si, siendo bello, benéfico y bueno para cada uno, lo son también para la comunidad en circulos simultáneamente irradiadores y convergentes. (Maia, 2011)

En definitiva, la ética social en la austeridad presenta varias dimensiones complementarias. Considerada desde el discurso gubernamental, se refiere a la posibilidad de atenuar el impacto de los sacrificios a los que obliga el programa de ajuste económico-financiero entre los grupos más necesitados de la población. Vista desde la óptica afín de la CNIS, su significado gana matices: designa la responsabilidad individual, el esfuerzo y la clarividencia para superar la exigencia de aquellos sacrificios renunciando a soluciones artificiosas y a la cultura de la dependencia. Para eso, contarán con las instituciones de la ES.

\section{La Economía Social como paliativo}

El XIX Gobierno reivindica una versión de la ES como instrumento para suavizar el impacto del PAEF mas sin cuestionar si tal impacto tiene o no su origen en las propias políticas de ajuste aplicadas. De un modo general y avanzo aquí parte de la argumentación que se ofrecerá a continuación, la noción de paliativo ilustra adecuadamente la visión proyectada de la ES desde la esfera gubernamental. Utilizo el término paliativo en su acepción original recogida en el Diccionario de la Real Academia Española de la Lengua, esto es, en el sentido de mitigar, atenuar o suavizar el dolor. En este caso, se trataría de aplicar una analogía con las dolosas consecuencias sociales derivadas de la crisis y del propio programa de ajuste económico-financiero y la movilización discursiva y operativa de la ES para contrarrestar tan perniciosos efectos. Es decir, la ES resulta instrumental en la medida en que constituye esa fuerza de choque frente a una situación crítica y unas políticas tildadas de inevitables y necesarias. Esta conceptualización como paliativo se construye a partir de tres dimensiones que demuestran cómo el XIX Gobierno nunca asume la ES como un proyecto político-económico distintivo con su potencial de crítica al sistema capitalista. La primera es su subordinación a los imperativos del Programa de Asistencia Económica y Financiera. La segunda, su relega- 
ción frente, sobre todo, a la lógica mercantil y en menor medida a la estatal; relegación que se materializa en el papel de compensación de las limitaciones del Estado y las asimetrías del Mercado. Y la tercera pasa por su mercantilización, contribuyendo deseablemente, según la óptica gubernamental, a la constitución de mercados o pseudo-mercados en el dominio de la acción y la protección social. Paso, pues, a desarrollar con más detalle cada una de estas dimensiones.

El punto de partida es la caracterización del país en términos de emergencia; una idea que resultó consensual entre amplios sectores de la opinión pública desde el inicio de la legislatura (Caldas e Ramos de Almeida, 2016). Ese estado de emergencia se relaciona con el aumento de la dimensión del Estado y su consiguiente intervención en la economía, acaparando recursos y financiación que se substraen a la iniciativa privada:

Los resultados del modelo de gobernación existente están hoy a la vista de todos. El Estado ha vivido claramente por encima de sus posibilidades; se ha registrado un aumento continuado de su peso y dimensión; se ha perdido competitividad y se ha agravado exponencialmente el endeudamiento externo. (Presidência do Conselho de Ministros, 2011:12)

Se imponen reformas dirigidas a reducir aquella dimensión e intervención. La excepcionalidad del momento justifica la inevitabilidad de las políticas que serán aplicadas:

El Gobierno entiende que la austeridad en el gasto del Estado, sujeta a modelos de eficiencia, constituirá un impulso para la mejora de la productividad, el incremento del potencial de crecimiento y la creación de empleo. (Presidência do Conselho de Ministros, 2011: 12)

Adviene un período de sacrificios con sus correspondientes costes sociales. Tales costes no podrán ser asumidos por un Estado cuyo volumen debe reducirse. Surge aquí la oportunidad para que la ES se convierta en un herramienta de combate a las consecuencias de las exigentes medidas que se antevén en una coyuntura fuera de lo común. Las palabras del Primer Ministro, Pedro Passos Coelho, en el I Congreso Internacional de la Economía Social, cuando se refiere a la necesidad de descentralizar, desburocratizar e desestatizar la solidaridad social, son una evidencia más en la imagen que se construye de la ES:

En este terreno, hay un conjunto de servicios que no puede ser suministrado por el mercado pero tampoco por mecanismos estatales que, inevitablemente, acaban siendo distantes, impersonales y burocráticos. (Coelho, 2013) 
Esta imagen corresponde a una visión correctora-compensadora de los fallos del mercado y las limitaciones del Estado en la provisión de bienes y servicios relacionados con la acción y la protección social. Mas, ¿qué presupuestos subyacen a esta visión de la ES? De acuerdo con Adaman y Adra (2002), desde esta perspectiva, la ES parece constituir una suerte de excepcionalidad en el campo de la actividad económica, naturalmente dominado por el Mercado y el Estado.

El presupuesto inicial resulta conocido y es canónico dentro de la teoría económica liberal y neoliberal (Almeida, 2011; Hansmann, 2006): el intercambio mercantil entre agentes económicos orientados según una racionalidad práctica que pretende la maximización de su utilidad mediante un análisis coste-beneficio. La dinámica entre la oferta y la demanda determina la cantidad de bienes y servicios producidos e intercambiados así como el precio al que se efectúa la transacción. El mercado, comandado por esta dinámica, se erige en la institución responsable del suministro de aquello que demanda una sociedad siendo la iniciativa particular de los agentes económicos el núcleo esencial de la economía.

Sin embargo, esta iniciativa, debido a la falta de incentivos relacionados con la expectativa de maximización de la utilidad, no genera bienes públicos: obtener beneficios en este terreno se hace complicado sin subvertir la lógica de este tipo de bienes. Por ese motivo, se arguye desde esta óptica, el suministro de aquellos bienes ha de corresponder al Estado hasta los niveles de satisfacción del votante mediano (Pereira, 1997). Ello permite atender a un contingente amplio de la población, lo que a su vez, puede reforzar la legitimidad del gobierno a ojos de sus potenciales o efectivos electores. Empero, en sociedades heterogéneas y complejas como las nuestras, la satisfacción del votante mediano supone dejar de lado otros contingentes de la población: existe demanda de bienes públicos más allá de la mediana, si bien se estima que sea residual y, por extensión, con una baja rentabilidad financiera y electoral para el Estado y sus gobernantes. He aquí el espacio de intervención para la ES: atender a la demanda no satisfecha ni por el Estado, centrado en la mediana de la población, ni por el mercado, sin incentivos para producir bienes públicos.

La atención a este tipo de demanda se ve favorecida también por la capacidad que la ES tiene para desempeñar una función esencial en el seno de la economía de mercado: compensar la ausencia o los vacíos de información existentes en cierto tipo de contratos (Almeida, 2011; Hansmann, 2006; Ortmann, 1996; Gui, 1991). Hay bienes y servicios que al ser adquiridos no permiten una evaluación clara de la relación que existe entre su calidad y el precio que los consumidores pagan por ellos: cuidado y atención de personas, actividades educativas o tareas médicas son algunos de los casos habituales. Cuando el consumidor paga, no es sencillo deter- 
minar si el prestador del servicio cuida, atiende, educa o cura con arreglo a lo que se espera del precio o si, por el contrario, su servicio es inferior en calidad a lo esperado. Se plantea una situación de información asimétrica que podría favorecer la aparición de conductas oportunistas en las que el prestador-vendedor ofrece un servicio según un precio que está por debajo de la calidad para maximizar su ganancia. La dificultad estriba, pues, en determinar ese grado de correspondencia.

Resolver este problema pasa por la instauración de un capital de confianza en la transacción, que emergería cuando de la misma desaparece la motivación maximizadora de la utilidad o, en otras palabras, la búsqueda de beneficio. Por eso, la ES sería llamada a intervenir en este escenario: cuando el bien o servicio no se suministra con arreglo a una motivación maximizadora y sí con arreglo a los principios de una organización con una finalidad social y solidaria, el consumidor se siente protegido frente a posibles conductas oportunistas. Es decir, la ES solventa la falta de información que dificulta la materialización del servicio.

En consecuencia, son las limitaciones de la lógica mercantil y de la redistribución estatal las que habilitan el espacio de la ES; un espacio que, según el discurso gubernamental, ha de responder a un principio de acuerdo público-social o, como afirmaba Pedro Mota Soares, de "welfare partnership system». Una de las formulaciones más evidentes de esta idea la hallamos en la entrevista que éste concedía a la Revista Popcom, editada por las juventudes de su partido, el CDS-PP. Mota Soares, cuando se le preguntaba por la importancia y eficacia de las instituciones sociales, insistía en su trascendencia y, a continuación, añadía:

Por eso queremos crear con ellas un nuevo paradigma de respuesta social. Un Estado Social de Acuerdo. El Estado no puede renunciar a sus responsabilidades —incluso muchas de ellas no son delegables - pero si puede contratar con las instituciones el complemento de su respuesta social con el propósito de tejer una red de solidaridad más fina y extensa. (Popcom, 2012: 27-28)

Esta nomenclatura, Estado Social de Asociación o Acuerdo u otras análogas — colaboración, contrato público-social — remiten para un tipo de racionalidad política que prevé la creación de mecanismos mercantiles en la prestación de servicios de protección y acción social. Estos mecanismos son el resultado de procesos políticos conducentes a la construcción de mercados en el área social, esto es, el gasto público se emplea en la dinamización de la iniciativa privada en la esfera de la acción y protección social (Costa e Rodrigues, 2008; Bode, Gardin e Nyssens, 2011). Esta es la pretensión esencial del neoliberalismo así como su propuesta fundamental en clave de organización social y reproducción material de la vida humana: 
la utilización de medios y procedimientos, entre los cuales figura el propio Estado con sus recursos y su aparato, para producir, coordinar o inducir mecanismos mercantiles en la vida social (Wacquant, 2012). Frente a ciertos discursos que se refieren al neoliberalismo como ideología, doctrina o ideario político que privilegian el mercado frente a un Estado reducido a la mínima expresión (Larner, 2000), entiendo el neoliberalismo como esa generación-creación-coordinación de mecanismos mercantiles que pueden incluir la participación del propio Estado (Abrahamson, 2010) y que, para el caso que nos ocupa, requiere la intervención y necesaria colaboración de las organizaciones de ES, especialmente de aquellas que concentran su actividad en el área de la acción y protección social (apoyos a niños/jóvenes/familias, cuidados asociados a vejez/invalidez, medicina preventiva/curativa, educación/formación profesional de adultos, insuficiencias en la vivienda). Uno de los más recientes trabajos para el caso portugués (Joaquim, 2015) confirma empíricamente este tipo de articulación entre la financiación estatal y organizaciones de la ES, lo que permite fijar un conjunto de consecuencias potenciales para la actividad de las mismas:

a) El campo de la acción social es, sin duda, el menos apetecible si se observa a través del prisma de los potenciales beneficios que, comparativamente, pueden provenir en mayor cuantía de la educación, la salud o la seguridad social (Hespanha, 2000). Con todo, no significa que no pueda ser abordado desde una perspectiva mercantil mediante la contratación por parte del Estado de ciertas respuestas sociales con ciertas organizaciones de la ES.

b) Además de la financiación procedente del Estado para determinadas prestaciones y servicios - un porcentaje por beneficiario y modalidad- las organizaciones de la ES que participan en este protocolo de colaboración estatal están en condiciones de obtener ingresos a partir de sus propios beneficiarios, a los que se les puede solicitar el copago en función de su capacidad económica. Esto puede constituir un incentivo para que la organización se oriente preferentemente hacia una población con mayor capacidad de copago abriendo la posibilidad de competir con otras organizaciones para captar a esos beneficiarios (Bode, Gardin y Nyssens, 2013).

c) Si tenemos en cuenta que el porcentaje por beneficiario y servicio es el mismo independientemente de las características de la IPSS, de sus infraestructuras, de su logística y de su capacidad para generar fondos propios, el sistema favorece a las organizaciones con una posición más robusta. Esa robustez puede venir dada por la existencia de condiciones - infraestructuras, personal, logística o 
economías de escala- de las que otras carecen. Simultáneamente, esto crea las condiciones de posibilidad para que se desarrollen estrategias que pueden enfocarse más a garantizar la supervivencia de la organización que a la prestación de servicios (Hespanha, 2000; Bode, Gardin y Nyssens, 2013).

\section{Conclusión}

La ES ocupó un espacio significativo en el discurso del XIX Gobierno Constitucional portugués. Se hizo presente en las declaraciones públicas de sus representantes y en una serie amplia de documentos oficiales aquí analizados. Este discurso le reservó un papel central en el combate a las consecuencias de la crisis y de las medidas asociadas al programa de ajuste económico-financiero.

Una de las principales justificaciones que se ofrecen para defender ese papel central tiene que ver con la imposibilidad de aumentar el gasto público: se espera que la ES pueda absorber el impacto social del ajuste sin necesidad de sobrecargar a un Estado que ha de reducir su peso y dimensión. A ello se le unen tres razones: proximidad de las organizaciones de ES a las poblaciones necesitadas, conocimiento directo de la realidad y experiencia acumulada. La confianza del Gobierno en la ES es el reverso de la desconfianza que manifiesta ante la iniciativa estatal en materia de protección y acción social. Esa iniciativa es tildada de ineficiente, derrochadora y burocráticamente rígida. De igual modo, aquella confianza es la evidencia palpable de la preocupación ética que subyace al programa de ajustes así como una prueba del sentido moral de la gobernación.

El discurso gubernamental también contempla una manera de pensar y ejecutar las políticas públicas de protección y acción social: un Estado Social de Acuerdo-Colaboración en el que la ES resulta decisiva. Al Estado le correspondería una parte substancial de la financiación y a la ES la ejecución de las políticas concretas. Así pues, las organizaciones de la ES forman parte del proceso de reformulación de las funciones del Estado a quien no compete, de acuerdo con este modelo, la prestación directa de servicios.

Sin embargo, el discurso gubernamental acerca de la ES no contempla necesariamente toda la variedad de organizaciones que la integran. $\mathrm{O}$, dicho de otro modo, se detecta una obvia distorsión pars pro toto, mediante la que se efectúa una asociación reductora entre ES y IPSS. A esto se le añade la ambigüedad terminológica con la que el discurso gubernamental aborda ambos conceptos. Aquella asociación es especialmente significativa en el caso del Programa de Emergencia Social, esto es, el conjunto de medidas que, paradigmáticamente, ilustra las expectativas que el XIX Go- 
bierno deposita en la ES, frecuentemente entendida como un corpus de IPSS. Por su parte, la ambigüedad se manifiesta en la falta de distinción entre formas organizativas y estatutos jurídicos: si atendemos, en sentido estricto, a las manifestaciones gubernamentales sobre la relevancia de la ES que aquí han sido reproducidas, éstas tienden a destacar la importancia de las IPSS, lo que, dentro del universo de la ES, continua siendo un estatuto minoritario: del total de 55.383 organizaciones, apenas 5.022 cumplen ese requisito.

Pero, fundamentalmente, para el XIX Gobierno Constitucional, la ES funciona como un paliativo: subordinada al programa de ajuste económico-financiero, relegada en favor de la lógica mercantil y, en menor medida, de la estatal-redistribuidora y mercantilizada en función de su contribución a la configuración de mercados en el área de la acción y protección social. El XIX Gobierno desarrolla una visión instrumentalizada de la ES, incluida en el intento de remodelación de las políticas públicas de acuerdo con el patrón de las políticas de austeridad. Estas últimas, con resultados críticos para amplias capas de la población (Hespanha, Ferreira y Pacheco, 2013), se presentan como inevitables y necesarias. En ese sentido, la ES no es convocada para discutirlas — circunstancia quizás esperable si tenemos en cuenta el proyecto político-económico derivado de los principios constitutivos de la ES - sino para evitar que sus efectos no se hagan excesivamente gravosos para aquellas capas de la población.

El alejamiento en relación a esos principios constitutivos supone difuminar el carácter distintivo de la ES. Existe un riesgo de isomorfismo institucional (Di Maggio y Powell, 1983), es decir, de aproximación — por el hecho de compartir el mismo medio, por influencia de los poderes políticos y de la legislación, por necesidad de legitimación ante la sociedad- a las organizaciones que operan mayoritariamente de acuerdo con una lógica mercantil. Evidentemente, ese riesgo lleva aparejada una consecuencia última: la imposibilidad de aplicar el concepto de ES a quien hace tiempo haya dejado de serlo.

\section{Referencias bibliográficas}

\section{Fuentes primarias}

AGÊNCIA LUSA (2011a): «Mota Soares defendeu ética social na austeridade em convenção europeia», Jornal Público, 17 de Octubre. En: http://www. publico.pt/sociedade/noticia/ministro-mota-soares-defendeu-etica-social-naausteridade-em-convencao-europeia-1516935 (acceso: 7 de noviembre de 2016). 
AGÊNCIA LUSA (2012): "Mota Soares defende novo paradigma de resposta social», Jornal Público, 27 de abril. En: https:/www.publico.pt/politica/noticia/ mota-soares-defende-novo-paradigma-de-resposta-social-1543870 (acceso: 7 de noviembre de 2016).

COELHO, P. (2013): Encerramento do I Congresso Internacional da Economia Social, Estoril, 29 de junho de 2013. En: http:/www.portugal.gov.pt/pt/o-governo/arquivo-historico/governos-constitucionais/gc19/primeiro-ministro/pm/intervencoes/20130629pm-cong-int-economia-social.aspx (acceso: 8 de noviembre de 2016).

COMISSÃO PERMANENTE DO SECTOR SOCIAL, CPSS (2013): Carta Comum de Balanço e Compromisso. En: http://www.portugal.gov.pt/pt/ogoverno/arquivo-historico/governos-constitucionais/gc19/os-ministerios/msss/ documentos-oficiais/20130604-msss-carta-balanco-compromisso-setor-social. aspx (acceso: 8 de noviembre de 2016).

CONSELHO NACIONAL PARA A ECONOMIA SOCIAL, CNES (2013): Carta de Cascais para a Economia Social. En: http://www.cases.pt/0_content/ DIC2013/Carta_de_Cascais_para_a_Economia_Social_pos_CNES.pdf (acceso: 8 de noviembre de 2016).

JORNAL DE NOTÍCIAS (2012). «Cantinas sociais vão receber 50 milhões de euros», 10 de Marzo. En: http://www.jn.pt/paginainicial/nacional/interior. aspx?content_id=2354203 (acceso: 7 de noviembre de 2016).

JORNAL I (2011). "OE 2012. 'Austeridade acautelou setores estratégicos da economia nacional' diz Mota Soares», 15 de outubro. En: http://www.ionline. pt/455052 (acceso: 7 de noviembre de 2016).

MAIA, L. (2011): Intervenção nas Jornadas Ética Social na Austeridade. En: http:// www.cds.parlamento.pt/gp/index.php?option=com_content\&view=article\&i $\mathrm{d}=1449 \% 3$ Aerica-social-na-austeridade $\&$ catid $=59 \% 3$ Ageral $\&$ Itemid $=64($ acceso: 8 de noviembre de 2016).

MINISTÉRIO DA SOLIDARIEDADE E DA SEGURANÇA SOCIAL, MSSS (2011), Programa de Emergência Social. En: http://www.portugal.gov.pt/pt/ogoverno/arquivo-historico/governos-constitucionais/gc19/os-ministerios/msss/ documentos-oficiais/20120704-pes.aspx (acceso: 8 de noviembre de 2016).

POPCOM (2012): "Entrevista a Pedro Mota Soares», Revista Popcom, 4, 22-29. En: http://cds-barcelos.com/?page_id=570 (acceso: 8 de noviembre de 2016)

PRESIDENCIA DO CONSELHO DE MINISTROS (2011): Programa do XIX Governo Constitucional. En: http://www.portugal.gov.pt/media/130538/ programa_gc19.pdf (acceso: 8 de noviembre de 2016).

PÚBLICO (2011): «Passos Coelho diz que Governo pode ir além das medidas da troika», Jornal Público, 6 de junio. En : https://www.publico.pt/economia/ noticia/passos-coelho-diz-que-governo-pode-ir-alem-das-medidas-da-troika1497781 (acceso: 8 de noviembre de 2016).

SOARES, P. (2011): Apresentação do Programa de Emergência Social. En: http:// www.portugal.gov.pt/pt/o-governo/arquivo-historico/governos-constitucionais/gc19/os-ministerios/msss/documentos-oficiais/20110805-programaemergencia-social.aspx (acceso: 8 de noviembre de 2016). 
TSF RÁDIO NOTÍCIAS (2011): «Ministro quer ética social nas tarifas da luz e do gás», 13 de Septiembre. En: http://www.tsf.pt/economia/interior/ministroquer-etica-social-nas-tarifas-da-luz-e-do-gas-1993166.html (acceso: 8 de noviembre de 2016).

\section{Fuentes secundarias}

ABRAHAMSON, P. (2010): «European welfare states beyond neoliberalismo: toward the social investment state», Development \& Society, 39 (1), 61-95.

ADAMAN, F. \& ADRA, Y.M. (2002): «Theorizing the 'Third Sphere': A critique of the persistence of the 'Economic Fallacy'", Journal of Economic Issues, 36 (4), 1045-1077.

ALESINA, A. \& ARDAGNA, S. (1998): «Tales of fiscal adjustment», Economic Policy, 13 (27), 489-545.

ALMEIDA, V. (2011): "Estado, Mercado e terceiro sector: a redefinição das regras do jogo", Revista Critica de Ciências Sociais, 95, 85-104.

BLYTH, M. (2013), Austerity: The History of a Dangerous Idea, Oxford University Press, Nueva York.

BODE, I., GARDIN, L. \& NYSSENS, M. (2013): "Quasi-marketisation in domiciliary care: varied patterns, similar problems?», International Journal of Sociology and Social Policy, 31(3/4), 222-235.

CALDAS, J. (2013): "O estado deve ser gerido como uma empresa?». In: J. Soeiro, M. Cardina y N. Serra (coords.), Não acredite em tudo o que pensa. Mitos do senso comum na era da austeridade, Tinta da China, Lisboa, 43-54.

CALDAS, J. \& RAMOS DE ALMEIDA, J. (2016): «Narrativas da crise no jornalismo económico", Cadernos do Observatório sobre crises e alternativas $n .^{\circ} 7$. Centro de Estudos Sociais, Coimbra.

CASES, Cooperativa António Sérgio para a Economia Social (2013): Conta Satélite da Economia Social 2010, Instituto Nacional de Estatística, Lisboa. En: http:// www.cases.pt/atividades/contasatelitees (acceso: 7 de noviembre de 2016).

CHAVES, R. (1997): «Economía política de la Economía Social», CIRIEC-España, Revista de Economía Pública, Social y Cooperativa, 25, 141-162.

CHAVES, R. \& MONZÓN, J.L. (2001): «Economía social y sector no lucrativo: actualidad científica y perspectivas», CIRIEC-España, Revista de Economía Pública, Social y Cooperativa, 37, 7-33.

COLANDER, D. (2005): "The making of an economist redux», Journal of Economic Perspectives, 19 (1), 175-198.

COSTA, A. C. \& RODRIGUES, J. (2008): «O nexo incomensurabilidade mercadorização e as limitaçóes da análise custo-benefício como guia de ação para os poderes públicos», Revista Critica de Ciências Sociais, 83, 141-163.

DEFOURNY, J. (2009): «Economia Social». In: A.D. Cattani, J.L. Laville, L.I. Gaiger \& P. Hespanha (orgs.), Dicionário Internacional da Outra Economia, Almedina-CES Coimbra, 156-161. 
DI MAGGIO, P. \& POWELL, W.W. (1983): «The iron cage revisited: Collective rationality and institutional isomorphism in organizational fields», American Sociological Review, 48 (2), 147-160.

FERREIRA, S. (2013): "Terceiro Sector e Estado Providência em Portugal». In: F. Carreira da Silva (org.), Os portugueses e o Estado-Providência, Imprensa de Ciências Sociais, Lisboa, 161-196.

FREIRE, A. (2013): "A crise como oportunidade e terapia de choque». In: E. Paz Ferreira (coord.), A austeridade cura? A austeridade mata?, Associaçáo Académica da Faculdade de Direito de Lisboa-AAFDL, Lisboa, 73-108.

FOURCADE, M., OLLION, E. \& ALGAN, Y. (2015): "The superiority of economists», Journal of Economic Perspectives, 29 (1), 89-114.

GUI, B. (1991): "The economic rationale for the Third Sector», Annals of Public and Cooperative Economics, 62 (4), 551-572.

GUIDDENS, A. (1998): The Third Way. The Renewal of Social Democracy, Polity Press, Cambridge (UK).

HANSMANN, H. (2006): «Economic Theories of Nonprofit Organization». In: W.W. Powell y R. Steinberg (eds), The Nonprofit Sector. A research handbook, Yale University Press, New Haven, Londres, 117-139.

HESPANHA, P. (2000): Entre o Estado e o Mercado. As fragilidades das instituiçóes de proteção social em Portugal, Quarteto, Coimbra.

HESPANHA, P. (2007): "The activation trend in the Portuguese social policy: An open process». In A. Serrano Pascual y L. Magnusson (Eds.), Reshaping Welfare States and Activation Regimes, Peter Lang, Pieterlen, 207-240.

HESPANHA, P., FERREIRA, S. \& PACHECO, V. (2013): «O Estado Social, crise e reformas». In: Observatório sobre crises e alternativas - Centro de Estudos Sociais, $A$ anatomia da crise. Identificar os problemas para construir as alternativas, Centro de Estudos Sociais-Universidade de Coimbra, Coimbra, 161-249.

HESPANHA, P. \& LUCAS DOS SANTOS, L. (2016): «O nome e a coisa. Sobre a invisibilidade e a ausência de reconhecimento institucional da Economia Solidária», Revista de Economia Solidária, 9 (en prensa).

JOAQUIM, C. (2015): "Proteção social, terceiro sector e equipamentos sociais», Cadernos do Observatório sobre crises e alternativas n. ${ }^{\circ}$ 3, Centro de Estudos Sociais, Coimbra.

LARNER, W. (2000): «Neo-Liberalism: Policy, Ideology, Governmentality», Studies in Political Economy, 63, 5-25.

LAVILLE, J.L. (2016): «L'economie solidaire face aux politiques publiques», $R e-$ vista de Economia Solidária, 9 (en prensa)

LAVILLE, J.L. \& NYSSENS, M. (2016): «Politiques Publiques», Ponencia presentada en I Fórum Português de Economia Social e Solidária. Lisboa, 13-14 de mayo de 2016.

MAMEDE, R. (2015): O que fazer com este país. Do pessimismo da razáo ao optimismo da vontade, Marcador Editora, Lisboa.

MOURY, C. \& FREIRE, A (2015): «A política e as políticas de austeridade: o caso português». In A. Freire, M. Lisi y J.M. Leite Viegas (Orgs.), Crise econó- 
mica, políticas de austeridade e representação política, Assembleia da República, Lisboa, 117-136.

MONZÓN, J.L. \& CHAVES, R. (2012): La Economía Social en la Unión Europea, Informe elaborado para el Comité Económico y Social Europeo por el Centro Internacional de Investigación e Información sobre la Economía Pública, Social y Cooperativa (CIRIEC). En: http://www.eesc.europa.eu/ resources/docs/qe-30-12-790-es-c.pdf (acceso: 8 de noviembre de 2016).

ORTMANN, A. (1996): «Modern economic theory and the study of nonprofit organizations. Why the Twain shall meet», Nonprofit and Voluntary Sector Quarterly, 25 (4), 470-484.

PEREIRA, P. (1997): «A teoria da Escolha Pública (public choice): uma abordagem neoliberal?», Análise Social, 141, 419-442.

POWELL, W.W. \& STEINBERG, R. (eds.) (2006): The Nonprofit Sector. A research handbook, Yale University Press, New Haven /Londres.

QUINTÃO, C. (2011): «O Terceiro Sector e a sua renovação em Portugal», Instituto de Sociologia da Universidade do Porto - IS Working Papers (2a série), 2.

SALAMON, L.M., ANHEIER, H.K., LIST, R., TOEPLER, S., SOKOLOWSKY, S.W. \& ASSOCIATES (1999): Global Civil Society. Dimensions of the Nonprofit Sector. The John Hopkins Center for Civil Society Studies, Baltimore.

SANTOS, A. (2013): «Temos vivido acima das nossas possibilidades». In J. Soeiro, M. Cardina y Nuno Serra (Coords.), Não acredite em tudo o que pensa. Mitos do senso comum na era da austeridade, Tinta da China, Lisboa, 17-29.

SEQUEIROS, R. (2013): «Gerir uma país é como gerir uma casa?». In J. Soeiro, M. Cardina y Nuno Serra (Coords.), Não acredite em tudo o que pensa. Mitos do senso comum na era da austeridade, Tinta da China, Lisboa, 31-41.

VAN DIJK, T. (2005a): «Política, ideología y discurso», Quorum Académico, $2(2), 15-47$.

VAN DIJK, T. (2005b): «Ideología y análisis del discurso», Utopía y Praxis Latinoamericana, 10 (29), 9-36.

VARELA, R. (2014): História do povo na revolução portuguesa. 1974-75, Bertrand, Lisboa.

WACQUANT, L. (2012): «Three steps to a historical anthropology of actually existing neoliberalism», Social Anthropology, 20 (1), 66-79.

\section{Páginas web}

BANCO DE PORTUGAL: Programa de Assistência Económica e Financeira. En: http://www.bportugal.pt/ptpt/estabilidadefinanceira/aestabilidadefinanceira paef/oprogramaassistenciafinanceiraportugal/Paginas/inicio.aspx (acceso: $10 \mathrm{de}$ noviembre de 2016). 